\title{
Aluminium phosphide poisoning: a prospective study of 16 cases in one year
}

\author{
J.S. Chopra, O.P. Kalra, V.S. Malik, R. Sharma and A. Chandna \\ Department of Medicine Unit V, Medical College Hospital, Rohtak, Haryana, India
}

\begin{abstract}
Summary: Sixteen patients suffering from aluminium phosphide poisoning were treated during the year from January 1985 to December 1985. These accounted for approximately half the total number of cases of acute poisoning. Profuse vomiting, pain in the upper abdomen and shock were the most common presenting features. Six patients succumbed to their illness. Analysis of various prognostic factors revealed that ingestion of 'unexposed' tablets of aluminium phosphide taken from a freshly opened bottle was associated with a greater risk of fatal outcome. Aluminium phosphide poisoning has become an important matter of public health in parts of India.
\end{abstract}

\section{Introduction}

Until recently, barbiturates, organophosphates and copper sulphate outnumbered all other types of poisoning in India (Wahl et al., 1963; Chuttani et al., 1965; Singh et al., 1984). During the last few years, however, we have seen a number of patients who have ingested aluminium phosphide, a commonly used grain preservative. To study this problem closely, we decided to keep a detailed record of all patients admitted in our unit with the diagnosis of suspected poisoning.

\section{Materials and methods}

Thirty three cases of acute poisoning admitted in our unit (which is one of six general medical units) in 1985 were studied prospectively. Of these, 16 were diagnosed as having ingested aluminium phosphide on the basis of a history of ingestion of aluminium phosphide tablets, as given by the attendants or by the patient himself. An enquiry was made as to whether the tablets ingested by the patients were taken from a freshly opened bottle or were lying exposed to the atmosphere. In 7 cases, the unused part of the substance ingested was retrieved from the patient or from his/her home and its analysis helped in confirming the diagnosis. Besides recording the signs and symptoms, a

Correspondence: J.S. Chopra, M.B., B.S., M.D., M.N.A.M.S., F.I.A.M.S.

Accepted: 17 June 1986 careful note was made of the approximate amount of aluminium phosphide ingested, period of onset of symptoms after ingestion and pre-hospitalization period. Patients were closely monitored particularly for the state of consciousness, vital signs, urinary output and any evidence of shock or of organ failure. Blood was examined for routine haematological and biochemical investigations. Complete urinalysis, a 12 lead electrocardiogram (in 13 cases) and chest X-ray (in 12 cases) were performed. Patients were managed by immediate stomach wash with normal saline, maintenance of airway, fluid and electrolyte balance and of nutrition. Shock was treated by conservative measures which included intravenous administration of appropriate fluids, dopamine infusion and hydrocortisone. No particular antidote was given.

\section{Results}

Details of the patients are given in Table I. Most of the patients presented with profuse vomiting and pain in the upper abdomen. Shock was another predominant feature (Table II). All the 6 fatal cases had intractable shock and died within half an hour to 3 days of admission.

Two patients developed mild elevation of blood transaminases and one a minor rise in serum bilirubin. Another patient developed significant proteinuria $(4.8 \mathrm{~g} /$ day $)$ which gradually disappeared over 10 days, and one patient developed renal failure. The elec-

\footnotetext{
The Fellowship of Postgraduate Medicine, 1986
} 
Table I Details of 16 patients with aluminium phosphide poisoning

\begin{tabular}{lc}
\hline Mean age (range) & $25(16-40)$ \\
Males & 13 \\
Mean number of tablets ingested* (range) & $2.6(0.5-8)$ \\
Mean duration of onset of symptoms (min) (range) & $48.4(0-120)$ \\
Mean pre-hospitalization period (h) (range) & $4.3(1-8)$ \\
Self poisoning & 13 \\
Accidental & 3 \\
\hline
\end{tabular}

* $3 \mathrm{~g}$ of aluminium phosphide/tablet.

trocardiogram revealed subendocardial infarction in 2 patients and transient atrial fibrillation in another.

Mean age, number of tablets ingested, period of onset of symptoms, pre-hospitalization period and presence of shock were similar in the patients who survived and those who died. The only factor which predicted a poor prognosis was the ingestion of 'unexposed' tablets. Out of 9 patients who ingested 'unexposed' tablets, all developed shock and of these 6 died. On the other hand, out of 7 patients who took 'exposed' tablets only 2 developed shock and none died $(P<0.05)$.

\section{Discussion}

Whereas barbiturates, organophosphates and copper sulphate were commonly used poisons in India till a few years ago (Wahl et al., 1963; Chuttani et al., 1965; Singh et al., 1984), aluminium phosphide is now rapidly becoming a very commonly used agent for self poisoning as revealed by the present study and also by others (Singh et al., 1985; Sepaha et al., 1985). Aluminium phosphide is used as a grain preservative, particularly for wheat. It is easily available over the counter and is marketed in India as Celphos, Quickphos, Synfume and Phosfume tablets of $3 \mathrm{~g}$ each containing $57 \%$ aluminium phosphide.

Apart from its easy availability, the other characteristic of aluminium phosphide is its highly lethal nature: 6 of our $16(37.5 \%)$ patients died. The experience of other workers is even worse: 11 out of 15 patients died in one series (Singh et al., 1985) and 16 out of $20 \overrightarrow{\vec{\omega}}$ patients in the only other series (Sepaha et al., 1985) reported so far. Its lethal characteristic is attributed to the fact that in the presence of moisture, aluminium phosphide releases phosphine (Childs \& Coates, 1971; Hackenberg, 1972) which is a colourless gas, which is quickly oxidized in the body and cannot be detected on analysis. Phosphine exposure has previously been reported in relation to fumigation of corn (Modrejewski \& Myslak, 1967) and bulk wheat (Jones et al., 1964; Heyndrieckx et al., 1976), transportation aboard a grain freighter (Wilson et al., 1980), attempted suicide (Zipf et al., 1967) and decomposition of ferrosilicon (Hunter, 1975).

Inhalation of phosphine gas in human beings causes severe pulmonary oedema. When aluminium phos phide is taken orally, phosphine is liberated in the stomach causing severe gastro-intestinal irritation and peripheral circulatory failure (Hunter, 1975), which may become intractable as in 6 of our 16 patients. In addition, it may also affect other organs such as heart, liver, kidney as revealed in the present study as well as others (Singh et al., 1985; Sepaha et al., 1985). The exact cause of intractable shock is not clear. Several factors such as myocardial damage, peripheral vasodilatation, fluid loss due to vomiting, severe epigastric pain and pulmonary oedema appear to be operative.

In the present study, the only factor which clearly distinguished survivors from non-survivors is the higher prevalence of ingestion of 'exposed' tablets in the former group $(P<0.05)$. It is possible that the

Table II Clinical features of aluminium phosphide poisoning

\begin{tabular}{lc}
\hline & No. of patients \\
\hline Profuse vomiting & 16 \\
Pain in abdomen & 13 \\
Shock & 11 \\
Marked tachycardia (heart rate $>120 / \mathrm{min})$ & 9 \\
Altered sensorium & 4 \\
Anuria & 1 \\
Pulmonary oedema & 1 \\
Fatal outcome & 6 \\
\hline
\end{tabular}


'exposed' tablets lose their toxicity because the atmospheric moisture reacts with aluminium phosphide to release phosphine, thus decreasing the potency of the tablet. It is probable that a larger proportion of our patients ingested 'exposed' aluminium phosphide tablets than those in the two other series (Singh et al., 1985; Sepaha et al., 1985) to account for the lower death rate.

The exact mechanism of action of aluminium phosphide is not known. However, it has been found to cause non-competitive inhibition of cytochrome oxidase of mitochondria in experimental animals (Chefurka et al., 1976). As a form of treatment, gastric lavage with potassium permanganate and intravenous magnesium sulphate has been tried in a small number

\section{References}

CHEFURKA, W., KASHI, K.P. \& BOND, E.J. (1976). The effect of phosphine on electron transport in mitochondria. Pesticide Biochemistry and Physiology, 6, 65.

CHILDS, A.F. \& COATES, H. (1971). The toxicology of phosphorus compounds. In Mellor's Comprehensive Treatise on Inorganic Chemistry, Vol. VIII. Suppl. III.The phosphorus volume. p. 1438. Longman: London.

CHUTTANI, H.K., GUPTA, P.S., GULATI, S. \& GUPTA, D.M. (1965). Acute copper sulphate poisoning. American Journal of Medicine, 39, 849.

HACKENBERG, U. (1972). Chronic ingestion by rats of standard diet treated with aluminium phosphide. Toxicology and Applied Pharmacology, 23, 147.

HEYNDRIECKX, A., PETEGHEM, C.V., HEEDE, M.V. \& LAUWAERT, R. (1976). A double fatality with children due to fumigated wheat. European Journal of Toxicology and Environmental Hygiene, 9, 113.

HUNTER, D. (1975). The other metals: Phosphorus. In The Diseases of Occupation, Hunter, D. (ed), 5th edition. p. 367. Hodder and Stoughton: London.

JONES, A.T., JONES, R.C. \& LONGLEY, E.O. (1964). Environmental and clinical aspects of fumigation of bulk wheat with aluminium phosphide containing tablets. American Industrial Hygiene Association Journal, 25, 376. of patients (Sepaha et al., 1985) but the results are yet to be confirmed.

The present study seeks to highlight the recent upsurge in the frequency of aluminium phosphide poisoning in this part of the world. However, because of its highly lethal nature, depressed patients with a high risk of suicide in the rest of the world also may soon be tempted to try this agent to end their real or imaginary misery.

The United Nations Organisation and its agencies WHO and FAO and others in consultation with state governments should quickly take appropriate steps to prevent further loss of lives as a result of self-poisoning with aluminium phosphide.

MODREJEWSKI, J. \& MYSLAK, Z. (1967). Phosphine poisoning during the fight against corn vermin in a port elevator (Polish). Medical Practitioner, 18, 78.

SEPAHA, G.C., BHARANI, A.K., JAIN, S.M. \& RAMAN, P.G. (1985). Acute aluminium phosphide poisoning. Journal of the Indian Medical Association, 83, 378.

SINGH, S., SHARMA, B.K., WAHI, P.L., ANAND, B.S. \& CHUGH, K.S. (1984). Spectrum of actute poisoning in adults (10 year experience). Journal of the Association of Physicians of India, 32, 561.

SINGH, S., DILAWARI, J.B., VASHIST, R., MALHOTRA, H.S. \& SHARMA, B.K. (1985). Aluminium phosphide ingestion in man. British Medical Journal, 290, 1110.

WAHL, P.K., LAHIRI, B., MATHUR, K.S., KEHAR, U. \& WAHI, P.N. (1963). Acute copper sulphate poisoning. Journal of the Association of Physicians of India, 11, 93.

WILSON, R., LOVEJOY, F.H., JAEGAR, R.J. \& LANDRIGAN, P.L. (1980). Acute phosphine poisoning aboard a grain freighter - epidemiological, clinical and pathological findings. Journal of the American Medical Association, 244, 148.

ZIPF, K.E., ARNOTT, T. \& HEINTZ, R. (1967). Klinische beobachtungen bei einen phostoxin Vergiftung. Archives of Toxicology, 22, 209. 